\title{
A SURVEY OF LANDNET SITES FOCUSING ON TUZ GÖLÜ SALT LAKE, TURKEY
}

\author{
S. Z. Gürbüz ${ }^{\mathrm{a}, \mathrm{b}, *}$, H. Özen ${ }^{\mathrm{a}}$, G. Chander ${ }^{\mathrm{c}}$
}

${ }^{a}$ TUBITAK Space Technologies Research Institute, Ankara, Turkey - (hilal.ozen, sevgi.gurbuz)@uzay.tubitak.gov.tr ${ }^{\mathrm{b}}$ TOBB Univ. of Economy and Technology, Dept. of Elec. and Electronics Eng., Ankara, Turkey - szgurbuz@etu.edu.tr ${ }^{\mathrm{c}} \mathrm{SGT}$, Inc., contractor to the U.S. Geological Survey (USGS) Earth Resources Observation and Science (EROS) Center, Sioux Falls, SD, 57198, USA - gchander@usgs.gov. Work performed under USGS contract G10PC00044.

\section{Commission I, WG I/4}

KEY WORDS: Remote Sensing, Satellite, Sensor, Calibration, Comparison, CEOS WGCV IVOS, LANDNET, Sites

\begin{abstract}
:
Radiometric calibration is critical to ensure the accuracy, veracity, continuity and reliability of satellite data measured from multiple sensors and platforms, and is thus recognized as a key activity by all satellite operators. For imaging sensors, vicarious methods using natural targets (such as salt lakes, deserts, or flatlands that are well-characterized and preferably temporally and spatially stable) as a reference are similarly well established. However, while selecting a target site, it is important that its quality and location are selected to minimize sources of uncertainty for any given sensor. To maximize the benefit from limited resources and minimize the impact on satellite operators, the Infrared Visible Optical Sensor (IVOS) sub-group of Committee on Earth Observation Satellites (CEOS) Working Group on Calibration and Validation (WGCV) has selected a few, well-characterized, regularly instrumented target sites, which have since become known as LANDNET sites. Currently, there are eight LANDNET sites: 1) Dome C, Antarctica; 2) Dunhuang, China, Asia; 3) Lspec Frenchman Flat, NV, USA, North America; 4) Ivanpah, NV/CA, USA, North America; 5) La Crau, France, Europe; 6) Negev, Southern Israel, Asia; 7) Railroad Valley Playa, NV, USA, North America; 8) Tuz Gölü, Central Anatolia, Turkey, Asia. This work summarizes the key characteristics, and areas of application of each of the LANDNET sites, especially that of Tuz Gölü, to guide and inform researchers on site selection, and increase international awareness and collaboration in this field. Additionally, detailed information about the Tuz Gölü, Turkey test site is provided, including geographical characteristics, spatial uniformity qualities, and opportunities for international researchers to conduct experiments and measurements. Practical, technical, and logistical experience gained through the international field campaigns organized over the last few years at Tuz Gölü is also shared in detail.
\end{abstract}

\section{INTRODUCTION}

Radiometric calibration is critical to ensure the accuracy, veracity, continuity and reliability of satellite data measured from multiple sensors and platforms. Absolute radiometric calibration, more specifically, refers to the conversion of the digital number (DN) of a pixel to absolute units, such as percentage reflectance value by using ground measurements of surface reflectance and atmospheric conditions to generate a radiative transfer code, which is in turn used to predict the sensor spectral radiance and compared with coincident satellite imagery. Vicarious methods that use natural targets (such as salt lakes, deserts, or flatlands that have known uniform area) as a reference are well established, but must be selected so as to minimize sources of error for any given sensor.

The criteria for selecting a test-site for the purpose of radiometric calibration have been defined by many authors (Scott, et. al., 1996; Thome, 2002; Morain and Budge, 2004; Teillet, et. al., 2007) and have been collated as a best-practice guide by the Committee on Earth Observation Satellites (CEOS) Working Group on Calibration and Validation (WGCV) Infrared and Visible Optical Sensors Group (IVOS) (USGS Test Site Catalog). Thus, a favorable test site should exhibit the following properties:

1. High spatial uniformity over a large area (within 3\%)

2. Surface reflectance greater than 0.3

3. Flat spectral reflectance

4. Temporally invariant surface properties (within 2\%)

5. Horizontal surface with nearly Lambertian reflectance
6. At high altitude, far from ocean, urban, and industrial areas, so that aerosols are minimized

7. In arid regions with low probability of cloud cover

There are many potential Earth targets that can be used as calibration test sites for optical sensors and these have been collated into a catalogue by the USGS on behalf of CEOS (Cal/Val Portal). However, data collection is expensive and requires significant effort. Moreover, the number of acquisitions from sensors is limited. Thus, CEOS WGCV decided to select a sub-set of sites that could focus international efforts, improve the interoperability of satellite assets, and improve traceability by reducing the uncertainty in measurements. In 2008, IVOS endorsed eight wellcharacterized, regularly instrumented test sites, now known as LANDET sites (Teillet and Fox, 2009), as well as the moon and five pseudo-invariant sites, for use as standard "CEOS test sites." These LANDNET sites (Fig. 1), endorsed by CEOS in 2009, are: 1) Dome C, Antarctica; 2) Dunhuang, China, Asia; 3) Lspec Frenchman Flat, NV, USA, North America; 4) Ivanpah, NV/CA, USA, North America; 5) La Crau, France, Europe; 6) Negev, Southern Israel, Asia; 7) Railroad Valley Playa, NV, USA, North America; and 8) Tuz Gölü, Central Anatolia, Turkey, Asia.

However, it is crucial that in addition to ensuring that the instrumentation used for field measurements is well-calibrated and traceable to SI units, the methodologies and procedures for data collection are standardized, and any differences between sites documented. 


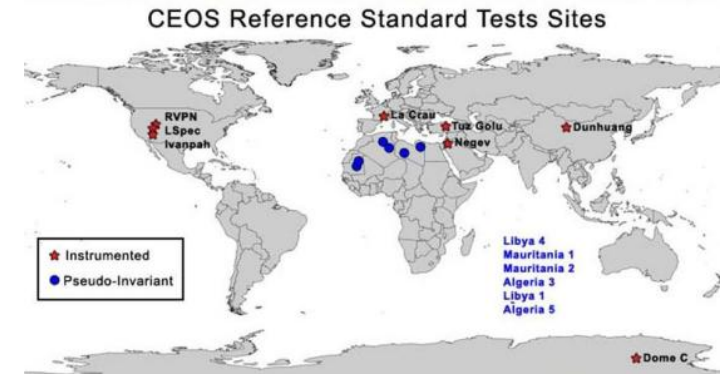

Figure 1. CEOS Reference Standard Test Sites (Fox, 2010)

IVOS thus decided to organize a measurement crosscomparison campaign at one specific reference site to quantify methodology biases. For this purpose, the Tuz Gölü salt lake in Turkey was chosen, and a pilot field campaign (Gürol, et. al., 2008) conducted in August 2008 by scientists from the National Physical Laboratory - NPL (UK) and TUBITAK Space Technologies Research Institute - UZAY (Turkey). A largerscale European comparison was organized in 2009, followed by a CEOS comparison in 2010, supported by the European Space Agency (ESA) project "Comparisons to Maintain Traceability for Optical Sensors (CONTROLS)." The 2010 field campaign (Özen, et. al., 2011; Boucher, et. al., 2011; Özen, 2010) was conducted with heavy international participation of teams from

- $\quad$ TUBITAK UZAY (Turkey),

- $\quad$ National Physical Laboratory - NPL (UK),

- $\quad$ French Aerospace Laboratory - ONERA (France),

- Flemish Inst. for Technological Res. - VITO (Belgium),

- National Aeronautics and Space Admin. - NASA (USA),

- Geo-Informatics and Space Technology Development Agency - GISTDA (Thailand),

- $\quad$ Korean Aerospace Research Institute - KARI (S. Korea),

- South Africa Council for Scientific and Industrial Research - CSIR (South Africa),

- Chinese National Satellite Metrological Centre NSMC/CMA (China),

- $\quad$ Brazilian Nat. Inst. for Space Res. - INPE (Brazil), and

- $\quad$ South Dakota State University - SDSU (USA).

Thus, one of the key goals of this paper is to summarize the key characteristics of Tuz Gölü and share practical, technical and logistical experiences gained from the field campaigns to aide researchers conducting radiometric calibration experiments at Tuz Gölü, and elsewhere. Moreover, the characteristics of each LANDNET site relevant to radiometric calibration measurements will be summarized with the goal of forming a concise source that can aide in site selection.

\section{LANDNET SITE SUMMARIES}

\subsection{DOME C, Antarctica}

The DOME-C test site $\left(-74.50^{\circ}\right.$ lat., $123.00^{\circ}$ long.) is a large, permanent snow field located in Antarctica (Fig. 2a), and thus possesses a very cold and dry climate, is low in aerosols and water vapor content, and is cloud-free more than $75 \%$ of the year. The site is extremely homogeneous, with a spatial variation less than $1 \%$, and has a high reflectance $(>0.7)$. Studies have shown DOME-C to have radiometric stability over 8 years for MODIS (channel 1 variation $<1.68 \%$ ) and AVHRR (band 2 variation <2.68\%) (Uprety and Cao, 2010). Measurements have a strong dependency on BRDF, but variations are minimal after BRDF normalization. Moreover, atmospheric ozone over DOME-C shows high variability of up to $14 \%$, significantly affecting broad band sensors such as AVHRR Band 1, and thus must be taken into account to reduce the uncertainty in the reflectance time series (Cao, et. al., 2010b). Generally speaking, DOME-C has been found to be most suitable for the calibration/validation of reflective solar bands in the 0.4-1.0 $\mu \mathrm{m}$ range (Cao, et. al., 2010c). However, key limitations include difficulty in accessibility as well as the availability of data only during the austral summer. Table 1 summarizes the site characteristics of DOME-C.

\subsection{Dunhuang, China, Asia}

The Dunhuang test site $\left(40.13^{\circ}\right.$ lat., $94.34^{\circ}$ long.) is located in the southern part of the Gobi desert and northwest end of the Qilian mountain range (Fig. 2b), conveniently just $1 \mathrm{~km}$ from the town of Qili and $35 \mathrm{~km}$ west of Dunhuang, China. Although the overall area of the Dunhuang site is $25 \mathrm{~km} \mathrm{x} 25$ $\mathrm{km}$, a $15 \mathrm{~km} \mathrm{x} 15 \mathrm{~km}$ area is used for low/medium resolution sensors (e.g., NOAA/AVHRR, FY-1/FY-3 imagers, EOS/MODIS), while a $400 \mathrm{~m} \times 400 \mathrm{~m}$ area is used for high resolution sensors (e.g., CBERS, Landsat TM).

The climate is arid, with extremely hot summers and bitterly cold winters. Dunhuang experiences just trace amounts of precipitation; however, the landscape is marked by strong winds and dust storms, which make atmospheric dust a key factor for about 60 days out of the year (Cao, et. al., 2010a). The site surface is comprised of gravel, sand and dust, with a cemented top layer that is $2.5 \mathrm{~cm}$ thick. Beneath this layer, the proportion of sand increases, while the uniform distribution of gravel on the site surface protects the desert soil from wind erosion. The rural location of Dunhuang enables a low aerosol optical depth, except during the dusty season, which lasts from March to May, affecting atmospheric transparency through June as well $(\mathrm{Hu}$, X., et. al., 2001; Hu, X., et. al., 2010). The site is spatially uniform, with variations of less than $2 \%$ over the central $10 \mathrm{~km}$ x $10 \mathrm{~km}$ region $(\mathrm{Hu}, \mathrm{X}$., et. al., 2010). The spectral reflectance is also basically flat over $600 \mathrm{~nm}$ to $1400 \mathrm{~nm}$ wavelengths (IVOS Questionnaire). However, over an 8 year period, reflectance measurements exhibited temporal variations of about $\pm 5.6 \%$ (Cao, et. al., 2010a). Moreover, the overall surface reflectance is relatively low $(\approx 0.2)$, while the surface has clear directional dependence and is not Lambertian, requiring BRDF correction to minimize variations. Table 1 summarizes the site characteristics of Dunhuang.

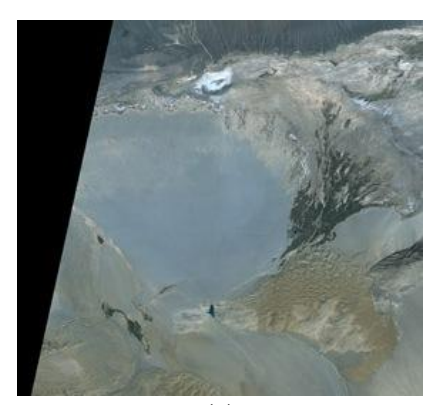

(a)

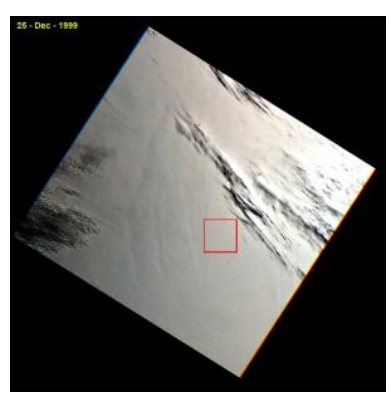

(b)
Figure 2. (a) Dunhuang (USGS); (b) DOME-C (USGS)

\subsection{Lspec Frenchman Flat, NV, USA, North America}

The Frenchman Flat test site $\left(36.81^{\circ}\right.$ lat., $-115.93^{\circ}$ long. $)$ is located $100 \mathrm{~km}$ northwest of Las Vegas, Nevada (Fig. 3a). A hard dry lake-bed, clay desert playa surrounded by light creo- 
International Archives of the Photogrammetry, Remote Sensing and Spatial Information Sciences, Volume XXXIX-B1, 2012 XXII ISPRS Congress, 25 August - 01 September 2012, Melbourne, Australia

Table 1. Summary of LANDNET Site Characteristics (Compiled from References)

\begin{tabular}{|c|c|c|c|c|c|c|c|}
\hline Site & Altitude & $\begin{array}{c}\text { Useable } \\
\text { Area } \\
\end{array}$ & $\begin{array}{c}\text { Spatial } \\
\text { Uniformity }\end{array}$ & Surface Reflectance & $\begin{array}{l}\text { Spectral } \\
\text { Flatness } \\
\end{array}$ & $\begin{array}{c}\text { Temporal } \\
\text { Variability } \\
\end{array}$ & Lambertian? \\
\hline DOME-C & $3215 \mathrm{~m}$ & TBD & $<1 \%$ & $>0.7$ & $\begin{array}{l}\text { Flat over } \\
0.4-1 \mu \mathrm{m}\end{array}$ & $\begin{array}{l}1.35 \% \text { change } \\
\text { over } 10 \text { years }\end{array}$ & $\begin{array}{l}\text { Yes, after } \\
\text { correction }\end{array}$ \\
\hline Dunhuang & $1220 \mathrm{~m}$ & $225 \mathrm{~km}^{2}$ & $<2 \%\left(100 \mathrm{~km}^{2}\right)$ & $\begin{array}{l}\text { VIS/NIR: } 0.15-0.25 \\
\text { SWIR : } 0.32\end{array}$ & $\begin{array}{c}\text { Flat over } \\
0.6-1.4 \mu \mathrm{m}\end{array}$ & $\begin{array}{l}<3 \% \text { variation } \\
\text { over } 7 \text { years }\end{array}$ & $\begin{array}{l}\text { Yes, after } \\
\text { correction }\end{array}$ \\
\hline $\begin{array}{c}\text { Frenchman } \\
\text { Flat }\end{array}$ & $940 \mathrm{~m}$ & $300 \mathrm{~m}^{2}$ & $\mathrm{~N} / \mathrm{A}^{++}$ & $0.5-0.9 \mu \mathrm{m}:>0.3$ & $\mathrm{~N} / \mathrm{A}$ & N/A & $\begin{array}{l}\text { Yes, for low } \\
\text { angles or after } \\
\text { correction }\end{array}$ \\
\hline Ivanpah & $813 \mathrm{~m}$ & $1 \mathrm{~km}^{2}$ & "good" & $>0.5 \mu \mathrm{m}: 0.3-0.55$ & $\begin{array}{c}\text { Flat over } \\
0.7-1.8 \mu \mathrm{m}\end{array}$ & $\begin{array}{l}\text { seasonal } \\
\text { variation }\end{array}$ & Yes, $<40^{\circ}$ \\
\hline La Crau & $28 \mathrm{~m}$ & $2 \mathrm{~km}^{2}$ & $\begin{array}{l}<2 \% \mathrm{VIS}^{*} \\
<4 \% \mathrm{NIR}^{* *}\end{array}$ & $\begin{array}{ll}>0.75 \mu \mathrm{m} & :>0.3 \\
0.4-1 \mu \mathrm{m} & : 0.1-0.4\end{array}$ & $\begin{array}{l}\text { Lin. over } \\
0.4-1 \mu \mathrm{m}\end{array}$ & $<0.4 \%$ & $\begin{array}{l}\text { Yes, after } \\
\text { correction }\end{array}$ \\
\hline Negev & $334 \mathrm{~m}$ & $0.2 \mathrm{~km}^{2}$ & $\begin{array}{l}<3 \% \text { except } \\
\text { near edges }\end{array}$ & $\begin{array}{l}0.50-0.59 \mu \mathrm{m}: 0.34-0.4 \\
0.61-0.68 \mu \mathrm{m}: 0.48-0.52\end{array}$ & $\begin{array}{c}\text { Flat over } \\
0.7-1.8 \mu \mathrm{m}\end{array}$ & $\begin{array}{l}\text { minimal most of } \\
\text { year }\end{array}$ & Yes \\
\hline Tuz Gölü & $905 \mathrm{~m}$ & $324 \mathrm{~km}^{2}$ & $2-4 \%$ & $\begin{array}{l}\text { VIS/NIR bands: } 0.4-0.6 \\
\text { SWIR } * * * \text { band: } 0.2\end{array}$ & $\begin{array}{l}\text { Flat over } \\
0.6-1 \mu \mathrm{m}\end{array}$ & $\mathrm{TBD}^{+}$ & Yes \\
\hline
\end{tabular}

*VIS: visible hand: **NIR: near-infrared hand: ***SWIR: short-wave infrared hand: ${ }^{+}$TBD: to be determined: ${ }^{++}$N/A: not available

-sote and sage scrub, the natural playa spans an area of roughly $3 \mathrm{~km} \mathrm{x} 4 \mathrm{~km}$. However, a majority of the playa surface is scarred by weapons testing debris, roads, buildings, bunkers and bridges, leaving a fairly clear area of $1000 \mathrm{~m}^{2}$ and a homogenous area of $300 \mathrm{~m}^{2}$. As a result, Frenchman Flat only supports sensors with footprints less than $300 \mathrm{~m}$. However, a key advantage is that this useable area has good surface homogeneity properties as well as infrastructure provided by the Non-Proliferation Testing and Evaluation Center (NPTEC). A $50 \mathrm{~m}^{2}$ area within the homogeneous region is instrumented by the LED Spectrometry Facility (Lspec) and capable of providing measurements of surface reflectance (ASD spectrometer, $1 \mathrm{~nm}$ sampling, 350-2500 $\mathrm{nm}$ spectral range); temporal surface reflectance (LEDs at eight discrete wavelengths); atmospheric data, including aerosol optical depth (AERONET Cimel \#9); meterological data, including wind speed and direction, temperature, relative humidity, pressure; and soil temperature (JPL Lspec website). In fact, measurements can even be requested online through the JPL Lspec Frenchman Flat Website. It has been observed by researchers that the Lspec test site consistently calibrates about 5\% higher than RVPN (Polder, et. al., 2010). Table 1 summarizes the site characteristics of Frenchman Flat.

\subsection{Ivanpah Playa, California, USA}

The Ivanpah Playa test site $\left(35.5692^{\circ}\right.$ lat., $-115.3976^{\circ}$ long.) is a dry lake-bed desert located in the Primm Valley spanning the California/Nevada border (Fig. 3b). Although it has smaller usable area $(1 \mathrm{~km} \times 1 \mathrm{~km})$ and lower elevation than RVPN, the Ivanpah test site is more convenient to use and exhibits better spatial uniformity (USGS Test Site Catalog). Ivanpah is low in aerosol loading and possesses a relatively flat spectral reflectance. Moreover, the surface is within $5 \%$ of a Lambertian surface for view angles less than $40^{\circ}$ (Hook, et. al., 2001).

However, spatio-temporal variability is seasonally dependent upon the amount of rainfall. One possible explanation for the dependence on rainfall is that during the wet season the surface is comprised of a mixture of clay with quartz. When the dry season comes during the late spring/early summer, wind exposes the quartz, thereby changing the spectral emissivity of the surface (Villa-Aleman, et. al., 2002). In fact, studies have shown that the location of the most homogenous region within Ivanpah changes with weather conditions, causing some researchers to propose evaluating the best test location prior to each radiometric calibration experiment (Pavri and Green, 1998). Table 1 summarizes the site characteristics of Ivanpah.

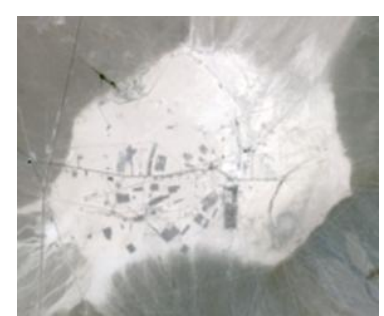

(a)

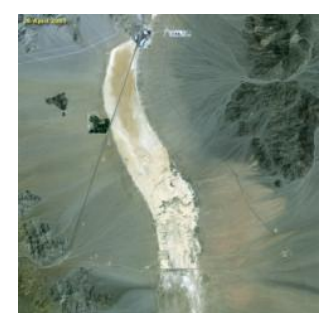

(b)
Figure 3. (a) Frenchman Flat (USGS); (b) Ivanpah (USGS)

\subsection{La Crau, France}

The La Crau test site $\left(43.56^{\circ}\right.$ lat., $4.86^{\circ}$ long.) is located $50 \mathrm{~km}$ from the French city of Marseille (Fig. 4a). The general terrain is comprised of thin pebbly soil covered with very sparse vegetation. In July, much of this vegetation is dry and dead due to the lack of rainfall for several months, but in late winter and spring, when the soil is wet, the vegetation turns green. Nevertheless, for much of the year, La Crau presents essentially a constant surface, and can be cloud-free for extended periods during the "Mistral" winds that blow in the valley. Although some irrigation canals cross the area, as well as several orchards established within $500 \mathrm{~m}$ of the test site, currently La Crau has been designated as a zone of "special protection" (Rondeaux, et. al., 1998), thereby inhibiting any construction that might affect measurements.

The general La Crau region spans an area of $15 \mathrm{~km} \times 15 \mathrm{~km}$, and has been investigated in terms of its suitability for radiometric calibration (Rondeaux, et. al., 1998); however, only a smaller $1 \mathrm{~km} \times 2 \mathrm{~km}$ section has been recognized as the LANDNET site, with an even smaller $400 \mathrm{~m} \times 400 \mathrm{~m}$ square used for calibrating the Satellite Pour l'Observation de la Terre (SPOT) satellites (Santer, et.al., 1992). The La Crau site 
possesses minimal spatial and temporal variability, and is essentially spectrally flat, exhibiting a minor linear increase in reflectance from 0.1 to 0.4 over the 400 and $1000 \mathrm{~nm}$ region (Gu, et.al., 1992). Due to significant sun angle effect (40\%), Bidirectional Reflectance Distribution Function (BRDF) correction is required to bring angular variations within $1 \%$ (Gu, et.al., 1992). The site's close proximity to the Mediterranean Sea and low altitude present the possibility of water vapour and aerosols affecting the measurements. A quantitative summary of site selection parameters is given for $\mathrm{La}$ Crau, as well as the other LANDET sites in Table 1.

\subsection{Negev, Israel}

The Shizafon playa test site in the Negev desert $\left(30.11^{\circ}\right.$ lat., 35.01 long.) is located in southern Israel, easily accessible at a distance of $120 \mathrm{~km}$ south (1 hour drive) of the Sede Boker campus of Ben Gurion University (Fig. 5). Although the total area of the Negev desert is approximately $10,000 \mathrm{~km}^{2}$, site selection studies within this area have shown that of 8 possible test sites, the Shizafon playa, with an overall area of $0.2 \mathrm{~km}^{2}$, exhibits the most desirable characteristics for radiometric calibration (Gilead, 2005). The Shizafon playa is located relatively far from the Mediterranean Sea, minimizing the influence of atmospheric water vapor. Annual precipitation is extremely low (40 mm/year), shielding the site from seasonal dynamics, which together with the lack of vegetation ensures the temporal stability of the site. The site also possesses high surface reflectance, good spatial and spectral uniformity, with a nearly Lambertian surface (Gilead, 2005). Table 1 summarizes the site characteristics of the Negev/Shizafon playa test site.

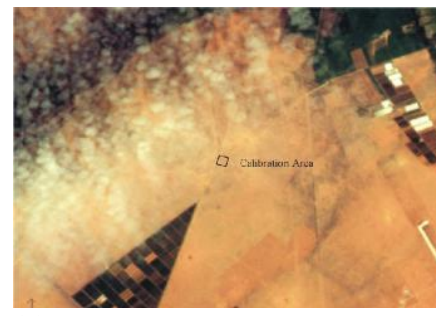

(a)

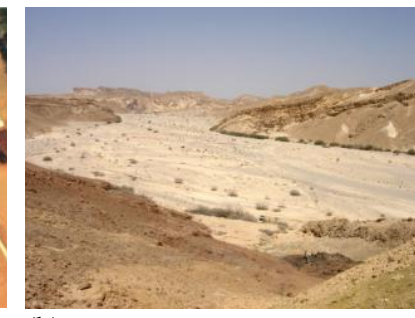

(b)
Figure 4. (a) La Crau test site (Schroeder, et. al., 1999);

(b) Shizafon playa in the Negev Desert (USGS)

\subsection{Railroad Valley Playa, Nevada (RVPN), USA}

The Railroad Valley Playa test site $\left(38.5^{\circ}\right.$ lat., $-115.69^{\circ}$ long.) is located 100 miles east of Tonopah, Nevada (Fig. 5a). It is a dry-lake playa, consisting of compacted clay-rich lacustrine deposites, which form a relatively smooth surface. On-site artifacts include roads as well as oil drilling structures. RVPN possesses a large usable area of $10 \mathrm{~km} \times 10 \mathrm{~km}$, which makes it suitable for the calibration of low spatial resolution sensors, such as National Oceanic and Atmospheric Administration (NOAA) Advanced Very High Resolution Radiometer (AVHRR), SPOT-4 Vegetation, EDS Moderate Resolution Imaging Spectroradiometer (MODIS), and MEdium Resolution Imaging Spectrometer (MERIS), as well as medium to high resolution satellites. However, its remote location and lack of infrastructure, including access to a cell tower that could enable the uploading of data, present limitations for ground-based studies (USGS Test Site Catalog).

Advantages of RVPN are that the surface is nearly Lambertian for view angles less than $30^{\circ}$ from nadir, spectrally flat over the band $0.6-2.0 \mu \mathrm{m}$, and that the site experiences low aerosol loading, with a high expectancy of clear weather. Moreover, the surface reflectance exceeds 0.4 for wavelengths larger than $500 \mathrm{~nm}$ (Thome and Smith, 2001), with good spatial uniformity. However, iron absorption (Fe3+) in the visible bands as well as the loose sands and salts, which present a soft surface composition, affect the spatio-temporal variability of the site. Studies indicate that spatial uniformity is maintained at from mid-summer to late fall (Bannari, et.al., 2004; Scott, et.al., 1996). Table 1 summarizes the site characteristics of RVPN.

\subsection{Tuz Gölü, Turkey}

The Tuz Gölü test site (Fox, et.al., 2009) (38.83 lat., 33.33 long.) is a permanent endorheic lake located in Central Anatolian plateau of Turkey (Fig. 5b), 150 southeast of Ankara and $105 \mathrm{~km}$ northeast of Konya. Thus, Tuz Gölü is easily accessible as well as logistically convenient, far from the influence of any bodies of water. During the summer, $95 \%$ of the water in the lake dries, leaving behind a smooth, uniform and flat $30-80 \mathrm{~cm}$ thick layer of salt over a region of $500 \mathrm{~km}^{2}$ (Gürol, et.al, 2008; Özen, et.al, 2009). It is possible to drive on the surface, but care must taken to avoid the springs discharging saline groundwater, which form $1 \mathrm{~m}-1.5 \mathrm{~m}$ circular structures, covered by just a thin layer of salt crust, on the surface. There is no vegetation on the dry salt lake; however, the lake is surrounded by fields and salt steppes, with three salt works operating on the shore of the lake. In 2001, Tuz Gölü was declared an area of special protection, thereby preventing future infrastructure projects in the area.

Tuz Gölü is a naturally bright target, with an average surface reflectance of 0.4-0.6 in the visible and near infrared bands (VIS/NIR), and 0.2 in the short wave infrared band (SWIR). An area of $324 \mathrm{~km}^{2}$ (Gürol, et.al, 2008; Özen, et.al, 2009) satisfies the homogeneity and reflectivity site selection criteria, making Tuz Gölü suitable for the calibration of low resolution as well as medium and high resolution sensors (Gürol, et. al., 2010). Limitations include high aerosol loading (optical thickness at $550 \mathrm{~nm}>0.1$ ) and the short period during the year for which the lake dries and is suitable for radiometric calibration measurements. Table 1 summarizes the site characteristics of Tuz Gölü.

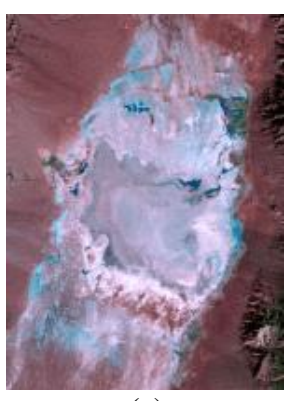

(a)

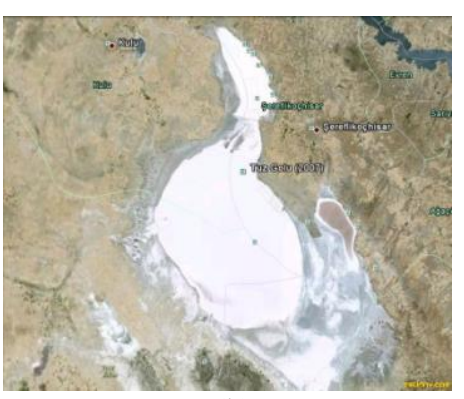

(b)
Figure 5. (a) RVPN (Thome, et.al., 2004);

(b) Tuz Gölü (Google Earth)

\section{TUZ GÖLÜ FIELD CAMPAIGN EXPERIENCES}

Through the field campaigns conducted at Tuz Gölü over the past three years and in particular the studies conducted under the ESA-funded CONTROLS project, much valuable experience about the practical and technical aspects of radiometric calibration measurements has been obtained. Field campaigns at Tuz Gölü are coordinated and logistically 
supported by TUBITAK UZAY. The dryness of the salt lake is continuously monitored during the summer to determine the optimal time for a field campaign. Typically, the lake is at its driest during August.

Once the campaign time frame is established, satellite imagery combined with a site survey is used to determine the best location within the lake for a field campaign. In 2010, a site location $3.5 \mathrm{~km}$ from the edge of the lake was selected, and comprised of eight $300 \mathrm{~m} \times 100 \mathrm{~m}$, one $1 \mathrm{~km} \mathrm{x} 1 \mathrm{~km}$, and one 3 $\mathrm{m} \times 50 \mathrm{~m}$ (named the "Thome Strip" after its originator, Dr. Kurtis J. Thome) measurement areas (Fig. 6). Two $50 \mathrm{~m}$ x $50 \mathrm{~m}$ areas were covered by black tarpaulins to demark the site location. Many techniques for demarking the site location have been tested, including dying the salt with food dyes; and plastic versus fabric tarpaulins. However, it has been found that the black fabric tarpaulins yield the most effective results. The borders of the measurement areas are flagged to ease finding the measurement area on the site. Typically, a whole day's work with several people is required to lay out the tarpaulins and to flag the borders of the measurement areas - a task accomplished during a pre-campaign site visit by TUBITAK UZAY scientists.

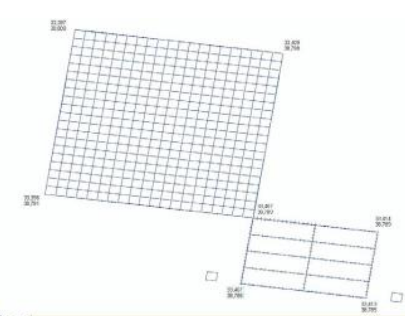

(a)

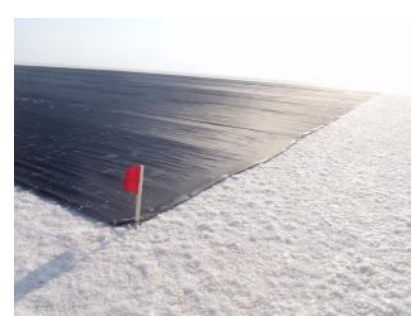

(b)
Figure 6. (a) Location of measurement areas and tarpaulins for the 2010 field campaign. (b) Close-up of black fabric tarpaulin.

The measurements are done at a time close to satellite image acquisition time or at a time when the sun zenith angle does not change much with time. The CEOS Visualization Environment (COVE) tool (Chander, et. al., 2010) was used to get the instrument coverage and coincident calibration opportunities between the instruments. As the temperatures on the salt lake easily exceed $40^{\circ} \mathrm{C}$ during the daytime, a camp is established on-site for protection and resting, as well as lodging, for those who prefer to spend the nights on the lake instead of in nearby hotels. Transportation on the salt lake is accomplished using an all-terrain vehicle (ATV) equipped with a trailer.

During the 2010 field campaign at Tuz Gölü, eight different teams employing multiple measurement strategies collected ground data. As the goal was to assess the effect of different measurement strategies on site characterization, satellite radiometric calibration, cross-comparisons were conducted in both laboratory and field environments (Behnert, et.al., 2011). At the optics laboratory of the near-by Middle East Technical University, Ankara, the reflectance panels of each team were compared to that of the NPL panel to normalize site reflectance values, while radiometers were compared against an NPL Transfer Standard Absolute Radiance Source (TSARS). Ground measurements included site surface reflectance (Fig. 7), sky radiance and solar irradiance, BRDF, atmospheric and meteorological measurements.

The results of this cross-comparison study are just recently coming out. Most notable was the inclusion of a special session in the 2011 International Geoscience and Remote Sensing

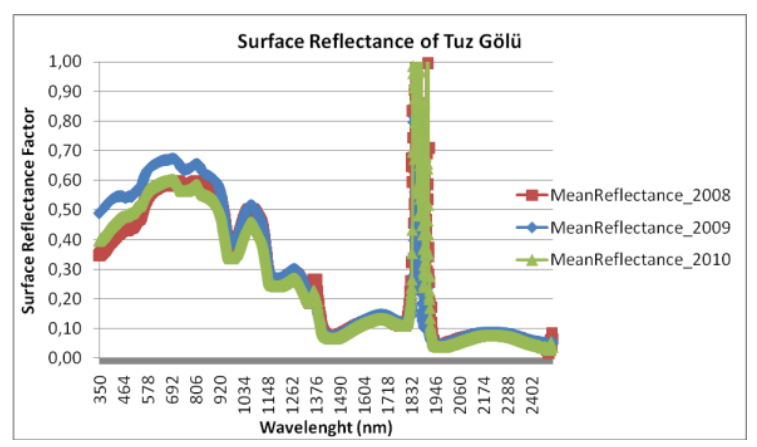

Figure 7. Surface reflectance of Tuz Gölü

Symposium (IGARSS) focusing on "Recent Advances in Multispectral Sensor In-Flight Calibration: The 2010 Tuz Golu Field Campaign," which included papers providing details on the study itself (Özen, et.al., 2011), site characteristics (Leigh, et.al., 2011), measurement strategies (Boucher, et.al., 2011), lessons learned (Thome and Fox, 2011), and laboratory panel and radiometer calibration (Deadman, et.al., 2011). At the end, it is hoped that this study will provide a key input for the development of best practices for the characterization and use of LANDNET sites in the post-launch radiometric calibration of optical satellites.

\section{CONCLUSION}

This paper provided a summary of site characteristics for each of the LANDNET sites, and, in particular, the Tuz Gölü salt lake in Turkey. Practical considerations for conducting field campaigns at Tuz Gölü were shared along with an update on the latest results of the 2010 CEOS cross-comparison campaign at Tuz Gölü.

\section{REFERENCES}

Bannari, A., Omari, K., Teillet, P.M., and Fedosejes, G., 2004. Multi-sensor and multi-scale survey and characterization for radiometric spatial uniformity and temporal stability of Railroad Valley Playa (Nevada) test site used for optical sensor calibration. Proceedings of SPIE, Vol. 5234, pp 590-604.

Behnert, I., A. Deadman, N. Fox, P. Harris, H. Özen, et. al., 2011. CEOS Key comparison of techniques and instruments used for the vicarious calibration of Land surface imaging through a ground reference standard test site 2010. QA4EO documentation, NPL, UK.

Boucher, Y., Viallefont, F., Behnert, I., Fox, N., Griffith, D., et. al., 2011. Spectral reflectance measurement methodologies for Tuz Gölü field campaign. IEEE IGARSS, Vancouver, Canada. Cao, C., Ma, L., Li, C., Tang, L., Uprety, S., 2010a. Spectral characterization of the Dunhuang calibration/validation site using hyperspectral measuements. Proc. SPIE, Vol. 7862.

\section{Cal/Val Portal: http://calvalportal.ceos.org}

Cao, C., Xiong, X., Uprety, S., Wu, A., et. al., 2010b. Results of DOME-C comparison for medium resolution sensors. CEOS WGCV IVOS Workshop, Ispra, Italy, Oct. 19, 2010.

Cao, C., Uprety, S., Xiong, X., Wu, A., Jing, P., et. al., 2010c. Establishing the Antarctic DOME-C community reference standard site towrads consistent measurements from earth observation satellites. Canadian J. Rem. Sens., Vol. 36, No. 5. 
Chander, G., Christopherson, J.B., Stensaas, G.L., \& Teillet, P.M. (2007). Online catalog of world-wide test sites for the post-launch characterization and calibration of optical sensors. Proc. of the 58th Int. Astro. Cong,, Vol. 3., pp. 2043-2051.

Chander, G., Killough, B., \& Gowda, S. (2010). An overview of the web-based Google Earth coincident imaging tool. IGARSS, Honolulu, HI, pp. 1679-1682.

\section{CEOS IVOS Test Site Questionairres for LANDNET sites.}

Deadman, A., Behnert, I., Fox, N., Griffith, D., 2011. Laboratory panel and radiometer calibration. IGARSS 2011.

Fox, N., H. Pegrum-Browning, I. Behnert, et. al., 2009. Tuz Gölü (Salt Lake) Turkey site characterization report. $Q A 4 E O$ document QA4EO-WGCV-IVO-CLP-001, NPL, UK, 2009.

Fox, N., 2010. Towards an "operational" metwork of instrumented test-sites: LANDNET. CEOS Presentation, 2010.

Gilead, U., 2005. Locating and examining potential sites for vicarious radiometric calibration of space multi-spectral imaging sensors in the Negev Desert. M.S. Thesis, Dept. of Solar Energy and Env. Physics, Ben-Gurion Univ. of the Negev.

Gu, X., Guyot, G., and Verbrugghe, M., 1992. Evaluation of measurement errors in ground surface reflectance for satellite calibration. Int. J. of Remote Sensing, Vol. 13, pp. 2351-2546.

Gürol, S., Özen, H., Leloğlu, U. M., Tunalı, E., 2008. Tuz Gölü: New Absolute Radiometric Calibration Test Site, WG I/1, ISPRS XXI Congress, Beijing, China.

Gürol, S., Behnert, I., Özen, H., et. al., 2010. Tuz Gölü: new CEOS reference standard test site for infrared visible optical sensors. Canadian J. Rem. Sens., Vol. 36, No. 5, pp. 553-565.

Hook, S.J., Myers, J.J., et. al., 2001. The MODIS/ASTER airborne simulator (MASTER) - A new instrument for earth science studies. Rem. Sens. of Env., Vol. 76, pp. 93-102.

Hu, X.Q, Zhang, Y.X., Liu, Z.Q., et. al., 2001. Optical characteristics of China radiometric calibration site for remote sensing satellite sensors (CRCSRSSS). Proc. SPIE, Vol. 4151.

Hu, X.Q., Liu, J., Sun, L., et. al., 2010. Characterization of CRCS Dunhuang test site and vicarious calibration utilization for Fengyun (FY) series sensors. Canadian Journal of Remote Sensing, Vol. 36, No. 5, pp 566-582.

JPL Lspec Frenchman Flat Website, https://lspec.jpl.nasa.gov

Leigh, L., Helder, D., Behnert, I., Deadman, A., et., al., 2011. Tuz Gölü site characteristics. IGARSS 2011, Vancouver.

Morain S., and Budge M. A., 2004. Post-Launch Calibration of Satellite Sensors, ISPRS Book Series - Volume 2, pp.181-187.

Özen, H., 2010. Results of Sensor comparison using Tuz Golu. CEOS WGCV IVOS Workshop, October 18-20, 2010, Italy.

Özen, H., S. Gürol, U. M. Leloğlu and E. Tunalı. Homogeneity analyses of Tuz Gölü with satellite images and ground data.
Turkish National Society for Photogrammetry and Remote Sensing Symposium, MTA, Ankara, Turkey, 04-06 Feb. 2009. Özen, H., N. Fox, U. M. Leloglu, I. Behnert and A. Deadman, 2011. The Tuz Gölü Field Campaign - an overview. IEEE IGARSS 2011, Vancouver, Canada.

Pavri, B., and Green, R., 1998. Calibration targets of the Southwest: Albedo and homogeniety comparisons using AVIRIS data. Proc. of AVIRIS Workshop, JPL Pub. 97-21.

Polder, M., Bruegge, C., Helminger, M., Taylor, M., 2010. Investigation of the Lspec autonomous ground calibration site using MODIS, Landsat ETM+, and IKONOS. Civil Commercial Imagery Evaluation Workshop, March 18, 2010.

Rondeaux, G., Steven, M.D., Clark, J.A., and Mackay, G., 1998. Int. J. Remote Sensing, Vol. 19, No. 14, pp. 2775-2788.

Santer, R., Gu, X., Guyot, G., Deuze, C., Vermote, E., and Verbrugghe, M., 1992. SPOT calibration at the La Crau test site. Remote Sensing of Environment, Vol. 41, pp. 227-237.

Schroeder, M., Muller, R., Reinartz, P., $1999 . \quad$ Vicarious Radiometric Calibration of MOMS at La Crau Test Site and Intercalibration with SPOT. ISPRS Workshop, Sep. 28-30, Hannover, Germany.

Scott, K. P., Thome, K., Brownlee, M. R., 1996. Evaluation of the Railroad Valley playa for use in vicarious calibration. Proceedings of SPIE, vol. 2818, pp. 158-166.

Teillet, P.M., Barsi, J.A., Chander, G., and Thome, K.J., 2007. Prime candidate earth targets for the post-launch radiometric calibration of space-based optical imaging instruments. Proceedings of SPIE, vol. 6677, 66770S.

Teillet, P.M., Fox, N., 2009. Concatenation of terrestrial reference standard test sites for systematic post-launch calibration monitoring of multiple space-based imaging sensors. Proceedings of SPIE, Berlin, Germany.

Teillet, P.M., \& Chander, G. (2010). Terrestrial reference standard sites for postlaunch sensor calibration. Canadian Journal of Remote Sensing, 36, 437-450.

Thome, K., 2002. Ground look radiometric calibration approaches for remote sensing imagers in the solar reflective. ISPRS Commission 1, Denver, CO USA.

Thome, K., and Smith, N., 2001. Vicarious calibration of MODIS using Railroad Valley Playa. IGARSS, Australia.

Thome, K., Czapla-Myers, J., Biggar, S., 2004. Railroad Valley Playa for use in vicarious calibration of large footprint sensors. CEOS IVOS Workshop, 12-14 October, Netherlands.

Thome, K., and Fox, N., 2011. 2010 CEOS field reflectance intercomparisons lessons learned. IGARSS 2011, Canada.

Uprety, S., and Cao, C., 2010. A comparison of the Antarctic DOME-C and Sonoran desert sites for the cal/val of visibl and near infrared radiometers. Proc. SPIE, Vol. 7811.

USGS Test Site Catalog,

http://calval.cr.usgs.gov/satellite/sites_catalog/ 